\title{
Direito Internacional dos Direitos Humanos e direito à água: uma perspectiva brasileira
}

Fecha de recepción: 14 de febrero de 2015

Fecha de aceptación: $1^{\circ}$ de septiembre de 2015

Doi: dx.doi.org/10.12804/acdi9.1.2016.05

\author{
César Yip* \\ Mariana Yokoya ${ }^{* *}$
}

Resumo: $\mathrm{O}$ artigo discute o reconhecimento do direito à água no direito internacional dos direitos humanos e suas implicações. Após mostrar as disputas relativas à interpretação desse direito, dá-se enfoque à contribuição brasileira quanto à sua incorporação no direito interno. Toma-se a jurisprudência sobre o corte de serviços de água por inadimplemento como estudo de caso para a questão do acesso à água e saneamento.

Palavras-chave: água, direitos humanos, saneamento.

* Bacharel em Direito pela Universidade de São Paulo e diplomata no Ministério das Relações Exteriores do Brasil. As opiniões expressas neste artigo representam a posição pessoal do autor, e não das instituições a que está vinculado. cesaryip@gmail.com ** Mestre em Ciências Sociais e doutoranda em Relações Internacionais pela Universidade de Brasília. Diplomata no Ministério das Relações Exteriores do Brasil. As opiniões expressas neste artigo representam a posição pessoal da autora, e não das instituições a que está vinculada. mariana.simoni@gmail.com

Para citar este artículo: Yip, César \& Yoyoka, Mariana, "Direito internacional dos direitos humanos e direito à água: uma perspectiva brasileira”, Anuario Colombiano de Derecho Internacional (ACDI), 2016, 9, pp. 167-195. Doi: dx.doi.org/10.12804/acdi9.1.2016.05 


\section{Derecho Internacional de los Derechos Humanos y Derecho al agua: una perspectiva brasilera}

Resumen: El artículo discute el reconocimiento del derecho al agua en el derecho internacional de los derechos humanos y sus implicaciones. Tras mostrar las disputas con respecto a la interpretación de ese derecho, se destaca la contribución brasileña respecto a su incorporación en el derecho interno. Se utiliza la jurisprudencia sobre la suspensión de suministro de agua por falta de pago como estudio de caso sobre la cuestión de acceso al agua y saneamiento.

Palabras clave: agua, derechos humanos, saneamiento.

\section{International Human Rights Law and the Right to water: a Brazilian Perspective}

Abstract: This article discusses the recognition of the right to water in international human rights law and its implications. After demonstrating the disputes with respect to the interpretation of this right, it outlines the Brazilian contribution in regard to its incorporation in domestic law. Jurisprudence on the suspension of water supply due to non-payment is taken as a case study of the question of access to water and sanitation.

Keywords: water, human rights, sanitation.

\section{Introdução}

A água é um elemento essencial para a sobrevivência humana. Ainda assim, a maioria dos tratados sobre direitos humanos não a menciona no seu rol de direitos garantidos. Essa contradição revela que o tratamento da água em seus diversos usos é, acima de tudo, uma disputa por formas alternativas de alocação e apropriação de um recurso cada vez mais escasso e valioso.

O presente artigo analisa a questão sob duas perspectivas. Em um primeiro momento, apresenta-se o processo de reconhecimento, delimitação e proteção do direito à água no direito internacional dos direitos humanos. Argumenta-se que a conformação do direito à água não é linear e tampouco está sujeita a uma única interpretação hegemônica, o que se 
busca explicitar a partir de uma oposição simbólica entre os foros de Nova Iorque e Genebra. Ainda assim, é possível tirar algumas conclusões e analisar a existência e a extensão de um direito à água no direito internacional dos direitos humanos a partir da prática e da opinio juris dos Estados e de casos de sistemas regionais de proteção aos direitos humanos. Esses aspectos são tratados nas seções 1, 2 e 3.

Em um segundo momento, desenvolvido na seção 4, analisa-se a perspectiva brasileira sobre a conformação do direito à água, identificando o tratamento da questão da água no ordenamento jurídico e a promoção do acesso à água nas políticas públicas. Ao final, analisa-se também a proteção conferida a esse direito no Poder Judiciário por meio da análise da jurisprudência relativa à possibilidade de corte do fornecimento de água em caso de inadimplência. $\mathrm{O}$ foco no caso brasileiro permite ressaltar a contribuição específica de um país em situação privilegiada, tanto por sua condição de país em desenvolvimento ${ }^{1}$ como por possuir a maior reserva de água doce do mundo. ${ }^{2}$ Com isso, espera-se poder aportar uma contribuição original para a literatura sobre o direito à água, em especial do ponto de vista do crescente debate sobre perspectivas latino-americanas a respeito dessa questão. ${ }^{3}$

\section{Existência e reconhecimento do direito à água}

$\mathrm{Na}$ presente seção, serão relacionados, inicialmente, os primeiros documentos internacionais nos quais há referencia direta ou indireta ao direito à água. Em seguida, busca-se explicitar as diferentes concepções que permeiam as Resoluções mais recentes sobre o tema no âmbito da Assembleia Geral da ONU (AGNU) e do Conselho de Direitos Humanos (CDH).

\footnotetext{
1 Embora não se adote explicitamente as abordagens metodológicas conhecidas como Third World Approaches to International Law (TWAIL), é importante demonstrar os interesses e interpretações relativas ao direito internacional a partir da perspectiva dos países em desenvolvimento, atendendo ao chamado, por exemplo, de Galindo, George Rodrigo Bandeira, "A volta do terceiro mundo ao direito internacional", Boletim da Sociedade Brasileira de Direito Internacional, 2013, 119-24, pp. 46-68.

2 Organização das Nações Unidas para Alimentação e Agricultura, Water Reports, $\mathrm{N}^{\circ} 23$ : Review of world water resources by country, 2003, p. 23.

3 Entre as contribuições mais recentes, destaque-se o trabalho, nesta mesma revista, de Murillo Chávarro, Jimena, "The right to water in the case-law of the InterAmerican Court of Human Rights", Anuario Colombiano de Derecho Internacional, 2014, 7, pp. 39-68.
} 
Por fim, indaga-se sobre a existência de um direito à água no âmbito do direito consuetudinário internacional.

\subsection{Arqueologia do direito à água}

Reconhecida como recurso essencial para a sobrevivência humana, a água não é mencionada nos principais documentos sobre a proteção dos direitos humanos, como a Declaração Universal dos Direitos Humanos e o Pacto Internacional sobre Direitos Econômicos, Sociais e Culturais (Pidesc). Pode-se inferir dessa omissão que os Estados tendem a considerar a água mais como recurso estratégico e bem econômico do que como um direito humano. Gleick, por outro lado, levanta a hipótese de que a água é tão fundamental que se considerou desnecessário incluí-la entre as referências nesses tratados. ${ }^{4}$

Há referências à garantia do fornecimento de água para consumo e higiene pessoal nas Convenções de Genebra de 1949 relativas à proteção das pessoas civis (artigos 89 e 127 da IV Convenção) e dos prisioneiros de guerra (artigos 20, 26, 29 e 46 da III Convenção). Não obstante a importância desses dispositivos para a proteção de civis internados e prisioneiros de guerra, não se pode superestimar seu significado quando se estuda a arqueologia do direito à água. Inicialmente, cumpre notar que o acesso à água é tratado nessas Convenções não como um direito, mas sim como um código de conduta para as Potências detentoras, no qual aparece ao lado de questões como a garantia do uso de tabaco e outros aspectos não relacionados aos direitos humanos. Em segundo lugar, e mais importante, ainda que se aceite a leitura de que o objetivo do direito internacional humanitário é humanizar a guerra, ${ }^{5}$ a lógica desse corpo normativo está mais pautada pelo interesse dos Estados no equilíbrio de obrigações recíprocas em momentos de conflito armado do que pelo reconhecimento de valores intrínsecos ou direitos inalienáveis do ser humano. ${ }^{6}$

\footnotetext{
4 Gleick, Peter H., "The human right to water", Water Policy, 1998, 1, (5), pp. 487-503.

5 Para uma leitura crítica desse objetivo declarado do direito humanitário, ver, por exemplo: Jochnik, Chris Af \& Normand, Roger, "The legitimation of violence: a critical history of the laws of war", Harvard Journal of International Law, 1994, 35, (1), pp. 49-95.

6 A garantia do acesso à água para fins de consumo e higiene apareceria ainda em outro documento multilateral relativo a situações de encarceramento, as Regras Mínimas para o Tratamento de Reclusos, adotadas pelo Primeiro Congresso das Nações Unidas sobre a Prevenção do Crime e o Tratamento dos Delinquentes, de 1955.
} 
O primeiro documento a afirmar de forma ampla e clara o direito à água é o Plano de Ação da Conferência das Nações Unidas sobre a Água, realizada em Mar del Plata, em 1977, em que se declara: "Allpeoples, whatever their stage of development and social and economic conditions, have the right to have access to drinking water in quantities and of a quality equal to their basic needs" 7 A linguagem do Plano de Ação é incisiva: coloca o direito à água potável como direito humano independente e ressalta a questão da quantidade e da qualidade. Essa formulação clara e assertiva aparece isolada na análise histórica do tema e não se repete em documentos posteriores.

Importante notar também que, até então, tratava-se de documento não vinculante, com caráter de soft law. $\mathrm{O}$ primeiro tratado a garantir o direito humano à água foi a Convenção para a Eliminação de Discriminação contra a Mulher, de 1979. Segundo o artigo 14 desse instrumento, os Estados deverão assegurar às mulheres em zonas rurais o direito a gozar de condições de vidas adequadas, incluindo serviços sanitários e acesso e abastecimento de água.

Note-se, ainda, a Convenção sobre o Direito das Crianças (1990), que em seu artigo 24, garante o direito à água em relação ao direito à saúde, mas somente trata do aspecto da potabilidade da água; a Convenção das Nações Unidas sobre o Direito dos Usos Não Navegacionais dos Cursos de Água Internacionais (1997), que, ainda que não verse especificamente sobre direitos humanos, estabelece, no caso de conflito entre usos concorrentes da água, a prioridade da sua utilização para atender às necessidades vitais $^{8}$ e a Convenção Internacional sobre os Direitos das Pessoas com Deficiência (2007), que ressalta o dever de não discriminação no acesso ao saneamento básico.

Posto que já estivesse mencionado em alguns tratados e declarações, no entanto, a formulação e desenvolvimento de um direito humano à água se deu principalmente a partir de 2002, com o Comentário Geral $\mathrm{N}^{\mathrm{o}} 15^{9}$ do Comitê sobre Direitos Econômicos, Sociais e Culturais (CDESC),

\footnotetext{
Organização das Nações Unidas, Report of the United Nations Water Conference, Mar del Plata, 14-25 March 1977, un Doc. E/CONF.70/29, Nova Iorque, 1977.

8 Artigo 10 (2): "In the event of a conflict between uses of an international watercourse, it shall be resolved with reference to articles 5 to 7 , with special regard being given to the requirements of vital human needs".

9 Organização das Nações Unidas, Conselho Econômico e Social, Comitê sobre Direitos Econômicos, Sociais e Culturais, General Comment No 15 (2002), un Doc. E/C.12/2002/11, Genebra, 29 nov. 2002 [doravante Comentário Geral No 15].
} 
órgão formado por especialistas independentes com o objetivo de avaliar o cumprimento dos dispositivos do Pidesc, que buscou esclarecer o alcance e as obrigações específicas derivadas desse direito a partir do Pidesc. ${ }^{10}$ São três os fundamentos do referido Comitê para afirmar que existe um direito humano à água. ${ }^{11}$

O primeiro diz respeito a uma interpretação telelógica do direito a um nível de vida adequado, garantido no artigo 11 do Pacto, que afirma: "Os Estados partes do presente Pacto reconhecem o direito de toda pessoa a nível de vida adequado para si próprio e sua família, inclusive à alimentação, vestimenta e moradia adequadas, assim como a uma melhoria contínua de suas condições de vida". O artigo não menciona a água, mas, segundo o Comitê, ao usar a palavra "inclusive", o Pacto é meramente ilustrativo, e não exclui outros elementos que seriam essenciais à qualidade de vida, como a água. ${ }^{12}$

Outro fundamento, para o Comitê, é o direito ao mais elevado nível possível de saúde física e mental (artigo 12), interpretado de forma extensiva, pois a água seria essencial para a manutenção da saúde humana. Com efeito, o Comitê afirma que o direito à água potável e ao saneamento é indissociavelmente associado ("inextricably linked") ao direito à saúde.

Por fim, o terceiro fundamento jurídico desenvolvido no Comentário é o fato de o Comitê ter precedentes em que analisou a situação da água e saneamento nos Estados partes do Pidesc desde a década de 1990. Assim, a aceitação tácita da competência do CDESC para tratar desse assunto poderia implicar o reconhecimento, pelos Estados, de que esse direito está contido no Pacto. Esse indício é questionável, pois o procedimento do Comitê não é adversarial, e sim do tipo cooperativo, de modo que os Estados buscam o compartilhamento de experiências e certo aprendizado

\footnotetext{
10 A International Law Association, por exemplo, refere-se ao Comentário como prova da existência do direito à água. International Law Association, Berlin Conference (2004), Water Resources Law, 2004, p. 24: "Any doubt about the existence of a right to water should be set to rest by General Comment 15".

11 Bulto, Takele Soboka, "The human right to water in the corpus and jurisprudence of the African human rights system", African Human Rights Law Journal, 2011, 11, (2), pp. 341-367.

12 Tully é crítico dessa abordagem, pois entende que se poderia delimitar melhor esse direito no contexto do direito à saúde, alimentação ou moradia. Tully, "A human right to access water? A critique of General Comment No 15", Netherlands Quarterly of Human Rights, 2005, 23, (1), p. 63.
} 
com as recomendações do Comitê, não estando necessariamente preocupados em refutar os argumentos jurídicos desse órgão. ${ }^{13}$

Com base nesses três pilares, o Comentário conclui que há um direito à água, o qual não teria de ser desenvolvido ou afirmado em tratados específicos, pois já seria uma realidade no direito internacional. Em outras palavras, esse direito precisaria apenas ser descoberto, e não inventado. ${ }^{14}$

\subsection{Entre Genebra e Nova Iorque}

O reconhecimento do direito à água foi tratado, até esse ponto da investigação, de forma linear, traçando um percurso evolutivo desde os primeiros documentos que mencionam a questão até as formulações mais avançadas do direito. No entanto, como alerta David Koller, é necessário superar narrativas tradicionais do direito internacional que traçam uma cartografia progressiva como se seu destino final fosse, desde o princípio, perfeito e pré-determinado, e desenvolver uma contra-narrativa que mostre o embate entre distintas propostas de regulação social passíveis de adoção pela sociedade internacional. ${ }^{15}$ No caso em análise, observa-se uma disputa entre diferentes concepções do direito humano à água, conforme interesses e motivações dos atores envolvidos na defesa da norma, o que tende a refletir-se em certa indefinição universal sobre esse direito.

Essa diferença pode ser identificada a partir de uma oposição simbólica entre as arenas políticas de Genebra (CDH) e Nova Iorque (AGNU). Mais do que uma separação geográfica, os dois enfoques refletem lugares privilegiados de disputa política entre diferentes concepções sobre a distribuição da água e o papel dos direitos humanos.

$\mathrm{Na}$ AGNU, o tema do direito humano à água é colocado em pauta em 1999, no contexto da discussão sobre o direito ao desenvolvimento. A Resolução 175 (LIV) da AGNU, em seu artigo 12.a, descreve o direito fundamental à água limpa, nos seguintes termos: "The rights to food and clean water are fundamental human rights and their promotion constitutes a moral

\footnotetext{
13 Bulto, “The human right...”, op. cit., p. 359.

14 Ibíd., p. 367: "The right requires discovery instead of invention".

15 Koller, David. “... and New York and The Hague and Tokyo and Geneva and Nuremberg and...: the geographies of international law", The European Journal of International Law, 2012, 23, (1), p. 100: "The metaphor of the physical journey serves deliberately to bighlight and to reinforce an underlying discourse of progressive development".
} 
imperative both for national governments and for the international community". ${ }^{16} \mathrm{E}$ importante ter em mente, portanto, que o direito à água volta à agenda internacional não por meio do direito internacional dos direitos humanos, mas da agenda desenvolvimentista.

Nessa arena, a busca pelo amplo reconhecimento de um direito humano à água tem a Bolívia ${ }^{17}$ como principal empreendedor da norma. ${ }^{18}$ A partir de proposta desse país, em julho de 2010, a Assembleia Geral das Nações Unidas adotou a Resolução 292 (LXII), que reconhece, "the right to safe and clean drinking water and sanitation as a human right that is essential for the full enjoyment of life and all human rights". ${ }^{19}$ A Resolução foi adotada com o voto favorável de 122 países e 41 abstenções.

O texto aprovado pela Assembleia Geral está fundamentado em argumentos desenvolvimentistas e destaca que, no ânimo de garantir esforços de prover saneamento e água limpa, segura e acessível para todos, é necessário que os Estados desenvolvidos e as organizações internacionais cooperem com os países em desenvolvimento. ${ }^{20} \mathrm{O}$ tom demandante $\mathrm{da}$ proposta boliviana deixa claro que o pleno gozo de água limpa e segura está condicionado ao nível de desenvolvimento de uma nação, do que derivaria o dever de cooperação financeira, técnica e tecnológica. Não por acaso, o documento foi discutido na agenda sob a seção "Promoção do crescimento econômico e desenvolvimento sustentável” (seção B), e não sob o tópico "Promoção dos direitos humanos" (seção D).

16 Organização das Nações Unidas, Assembleia Geral, Resolução 54/175, The right to development, un Doc. A/RES/54/175, Nova Iorque, 17 dez. 1999.

17 O protagonismo de Bolívia e Equador no reconhecimento e promoção do direito humano à água é tratado, entre outros, por: Wolkmer, Antonio Carlos; Augustin, Sergio; Wolkmer, Maria de Fátima S., "O 'novo' direito à água no constitucionalismo da América Latina", in Wolkmer, Maria de Fátima S. \& Melo, Milena Petters (Orgs.), Crise ambiental, direitos à água e sustentabilidade: visões multidisciplinares,Educs, Caxias do Sul, 2012, pp. 76-65.

18 Referimo-nos aqui ao conceito de norm entrepeneur, desenvolvido em Finnemore, Martha \& Sikkink, Kathryn, "International norm dynamics and political change", International Organization, 1998, 52, (4), pp. 887-917.

19 Organização das Nações Unidas, Assembleia Geral, Resolução 64/292, The human right to water and sanitation, UN Doc. A/RES/64/292, Nova Iorque, 28 jul. 2010 [Resolução 64/292].

20 Resolução 64/292, \$2: “Calls upon States and international organizations to provide financial resources, capacity-building and technology transfer, through international assistance and cooperation, in particular to developing countries, in order to scale up efforts to provide safe, clean, accessible and affordable drinking water and sanitation for all". 
Já em Genebra, no âmbito do CDH, foram países europeus, sobretudo Alemanha e Espanha, que tomaram a liderança e patrocinaram o reconhecimento de um direito humano à água. Em 2006, o Conselho adotou a Decisão 2/104 (2006), que solicitou ao Alto Comissariado sobre Direitos Humanos um estudo sobre o tema. ${ }^{21}$ A redação da resolução é cuidadosa e não faz referência a um direito humano à água, mas sim a obrigações de direitos humanos relacionadas ao acesso seguro à água potável e saneamento. Assim, o CDH não apenas se abstém de afirmar a existência de um direito humano autônomo, como limita essas obrigações à questão da água potável e saneamento. Essa linguagem repete-se na Resolução 7/22 (2008), que cria o cargo de Perito Independente para a temática. ${ }^{22}$

Com a criação dessa função, tem início o chamado "Geneva Process", um processo de colaboração da perita designada, a portuguesa Catarina de Albuquerque, com os esforços dos citados países no CDH para o reconhecimento da água como direito humano. ${ }^{23} \mathrm{Em} 2010$, após o trabalho da perita, o Conselho, por meio da Resolução 15/9 (2010), decidiu: "Affirms that the human right to safe drinking water and sanitation is derived from the right to an adequate standard of living and inextricably related to the right to the highest attainable standard of physical and mental health, as well as the right to life and buman dignity". ${ }^{24}$

Desde então, o Conselho de Direitos Humanos vem adotando novas resoluções (18/1, de 2011, e 21/2, de 2012) acompanhando os

21 Organização das Nações Unidas, Conselho de Direitos Humanos, Decisão 2/104, Human rights and access to water, Genebra, 27 nov. 2006: "Request the Office of the United Nations High Commissioner for Human Rights, taking into account the views of States and other stakebolders, to conduct, within existing resources, a detailed study on the scope and content of the relevant buman rights obligations related to equitable access to safe drinking water and sanitation under international human rights instruments, which includes relevant conclusions and recommendations thereon, to be submitted prior to the sixth session of the Council".

22 Organização das Nações Unidas, Conselho de Direitos Humanos, Resolução 7/22, Human rights and access to safe drinking water and sanitation, UN Doc. A/HRC/RES/7/22, Genebra, 28 mar. 2008.

23 McGraw, George S., "Defining and defending the right to water and its minimum core: legal construction and the role of national jurisprudence", Loyola University Chicago International Law Review, 2011, 8, (2), p 19.

24 Organização das Nações Unidas, Conselho de Direitos Humanos, Resolução 15/9, Human rights and access to safe drinking water and sanitation, UN Doc. A/HRC/RES/15/9, Genebra, 30 set. 2010. 
desenvolvimentos mais recentes sobre o tema, sobretudo o trabalho da relatora especial. ${ }^{25}$

É importante ressaltar alguns aspectos específicos sobre a vertente genebrina do direito à água. Primeiramente, ainda que afirme a existência de um direito à água potável e ao saneamento, na Resolução do CDH, esse direito é derivado do direito às mais altas condições de saúde, do direito à vida e do direito à dignidade humana. Em segundo lugar, essa perspectiva limita esse direito ao acesso à água potável segura e saneamento, deixando em nível secundário outras possíveis utilizações da água. Por fim, e mais importante, deve-se destacar o aspecto privatista da vertente genebrina. Patrocinadas por países europeus, essas resoluções possuem grande nível de detalhamento e privilegiam a prestação de serviços de água e saneamento por delegação a atores privados, em detrimento de outras possibilidades de prestação desse serviço (provisão direta pelo Estado e provisão informal). Nesse aspecto, cabe apontar que a Resolução 15/9, ao tratar da responsabilidade dos atores pela implementação desse direito (parágrafo $5^{\circ}$ ), usa termos diferentes em relação ao Estado (obligations) e a entes não estatais (responsibilities), o que pode ser visto como uma forma de mitigar a responsabilidade destes últimos. Esse mesmo desequilíbrio está presente no Comentário 15 do CDESC. ${ }^{26}$

Desse modo, os promotores da norma em Genebra favorecem um direito à água derivado de outros direitos, limitado à água potável segura e ao saneamento, e que seja prestado preferencialmente por delegação do Estado a atores privados. Essa concepção é claramente contrastante à vertente nova-iorquina, em que o direito à água está relacionado a conceitos amplos de desenvolvimento, e no qual provimento de água é responsabilidade primordial dos Estados, que em caso de não disporem de recursos e tecnologias, podem ser ajudados por Estados mais desenvolvidos e organizações internacionais.

\footnotetext{
25 A Resolução 16/2 do CDH renovou o mandato de Catarina de Albuquerque e mudou seu título de Perita Independente para Relatora Especial. Organização das Nações Unidas, Conselho de Direitos Humanos, Resolução 16/2, The human right to safe drinking water and sanitation, UN Doc. A/HRC/RES/16/2, Genebra, 24 mar. 2011, $\$ 4$.

26 Tully, "A human right to access water?...", op. cit., pp. 53-54: "The Committee's expectations are unimaginatively skewved against governments".
} 


\subsection{Direito costumeiro}

Como se verificou nas seções anteriores, o direito à água aparece de forma implícita ou setorizada nos tratados internacionais e de forma mais ampla em declarações e resoluções sem força de tratado. Ainda assim, a existência desse direito pode ser mais bem analisada do ponto de vista do costume internacional, entendido como prova de uma prática geral aceita como sendo direito, nos termos do artigo 38 do Estatuto da Corte Internacional de Justiça. Pode-se tomar como exemplo de prática internacional a inclusão do direito em diversas legislações nacionais, sua defesa e adjudicação em tribunais interno ${ }^{27}$ e a adoção de metas como a redução pela metade da população sem acesso a água potável e esgotamento sanitário como um dos Objetivos de Desenvolvimento do Milênio. Ao mesmo tempo, a opinio juris pode ser inferida do apoio que os Estados conferem às diversos tratados, resoluções e outros documentos sobre o assunto.

A partir da análise dos trabalhos preparatórios das resoluções tanto do CDU quanto da AGNU, é possível verificar que, ainda que com concepções distintas, a maioria dos Estados parece anuir com a tese de que existe um direito humano à água potável e ao saneamento. O status jurídico desse direito, entretanto, ainda é frágil. Em especial, questionase se sua existência se daria na forma de um direito humano autônomo ou derivado de outros direitos. A esse respeito, Amanda Cahill entende que a peculiaridade do direito à água, ao mesmo tempo independente $\mathrm{e}$ dependente de outros direitos, tais como saúde e nível de vida, faz dele um direito com status único no direito internacional. ${ }^{28}$

A questão não possui importância meramente acadêmica. Caso se trate de um direito derivado, sua proteção depende da violação do direito principal. Da mesma forma, sua extensão também está relacionada à proteção do direito principal. ${ }^{29}$ Assim, por exemplo, se estiver subordinado ao direito à vida, o direito à água limita-se à quantidade e qualidade de água

\footnotetext{
27 Ver, por exemplo, levantamentos feitos em Langford, Malcolm, "Ambition that overleaps itself? A response to Stephen Tully's critique of the General Comment on the right to water", Netherlands Quarterly of Human Rights, 2006, 24, (3), p. 443; e McGraw, "Defining and defending...", op. cit., pp. 47-85.

28 Cahill, Amanda, "The human right to water - a right of unique status': the legal status and normative content of the right to water", The International Journal of Human Rights, 2005, 9, (3), pp. 389-410.

29 Bulto, “The human right...", op. cit., pp. 347-348; Cahill, "The human right to water...", op. cit., p. 394.
} 
necessária para garantir a vida humana. Da mesma forma, sua derivação exclusiva do direito à alimentação negligenciaria utilizações fundamentais, como a questão do saneamento básico.

Tendo em vista o volume de documentos e a quantidade de oportunidades nas quais os Estados voluntariamente manifestaram aceitação dessa norma, assim como dada sua consagração no ordenamento jurídico nacional, parece claro que o direito humano à água potável e ao saneamento é entendido como um direito autônomo no âmbito do direito internacional dos direitos humanos. No entanto, uma vez que não é protegido de forma independente e detalhada em nenhum tratado de direitos humanos, esse direito deve ser interpretado sempre de forma conjunta com os direitos à vida, à saúde, à alimentação e a um nível de vida adequado, até para que possa gozar de maior proteção internacional.

\section{Extensão do direito à água}

Uma vez que se entenda que existem obrigações de direitos humanos relativas à água, é necessário analisar qual a extensão desses direitos. A análise dos documentos efetivamente negociados e aprovados pelos Estados revela que o direito humano à água, no atual estágio do desenvolvimento internacional, trata somente do direito à água potável segura e ao saneamento, ou seja, a água para utilização doméstica e pessoal. Referências a outras utilizações possíveis da água, como agricultura ou recreação, ${ }^{30}$ são legítimas, mas, pelo menos sob a perspectiva do direito internacional dos direitos humanos, são abordagens de lex ferenda, mais do que de lex lata, ${ }^{31}$ uma vez que não foram acolhidas na prática dos Estados.

Apoiando-se no Comentário 15, a International Law Association buscou compilar as normas relativas ao direito à água, ao atualizar regras de Helsinki, de 1996. O artigo 17 do documento aprovado na Conferência de Berlim afirma:

\footnotetext{
30 Hiskes, Richard P., "Missing the green: golf course ecology, environmental justice, and local 'fulfillment' of the human right to water", Human Rights Quarterly, 2010, 32, (2), pp. 326-341.

31 Ver, por exemplo, Murthy, Sharmila L., "The human right(s) to water and sanitation: history, meaning and the controversy over privatization", Berkeley Journal of International Law, 2013, 31, (1), pp. 36-37.
} 
1. Every individual has a right of access to sufficient, safe, acceptable, physically accessible, and affordable water to meet that individual's vital human needs.

2. States shall ensure the implementation of the right of access to water on a non-discriminatory basis.

3. States shall progressively realize the right of access to water by:

a) Refraining from interfering directly or indirectly with the enjoyment of the right;

b) Preventing third parties from interfering with the enjoyment of the right;

c) Taking measures to facilitate individuals access to water, such as defining and enforcing appropriate legal rights of access to and use of water; and d) Providing water or the means for obtaining water when individuals are unable, through reasons beyond their control, to access water through their own efforts. 4. States shall monitor and review periodically, through a participatory and transparent process, the realization of the right of access to water. ${ }^{32}$

Para fins de sistematização, é possível analisar essas normas sob três perspectivas: direitos subjetivos, deveres dos Estados perante seus cidadãos, e deveres dos Estados perante a sociedade internacional.

\subsection{Direitos subjetivos}

O Comentário 15 afirma que o direito à água resulta em liberdades (freedoms) e titularidades (entitlements) aos cidadãos. Segundo o Comitê, as liberdades significam o direito de manter acesso às fontes de água necessárias para garantir o direito à água e a liberdade de interferências, como desconexões arbitrárias ou contaminação das fontes de água. As titularidades, por outro lado, consistem no direito a um sistema de suprimento com igualdade de oportunidades a todos desfrutarem do direito à água.

Ainda segundo o Comitê, os direitos relacionados à água devem ser adequados, o que implica três fatores: disponibilidade, qualidade e acessibilidade.

As pessoas têm direito à disponibilidade de água em quantidade suficiente para usos pessoais e domésticos. O primeiro rascunho do Comentário 15 tentava delimitar quantidades específicas para esse quesito, ${ }^{33}$ mas o Comitê resolveu por bem não estabelecer nenhum critério rígido, referindo-se genericamente às diretrizes da Organização Mundial da Saúde.

\footnotetext{
32 International Law Association, Berlin Conference (2004), op. cit.

33 Cahill, “The human right to water...”, op. cit., p. 392.
} 
A qualidade da água garantida por esse direito pode ser definida negativamente, como a água que não constitua uma ameaça à saúde. Nesse aspecto, fica clara a relação do direito à água com o direito à saúde.

A acessibilidade da água deve ser garantida a todos sem discriminação. O Comitê destaca quatro aspectos da acessibilidade. Primeiramente, os serviços de água devem estar ao alcance físico seguro de todos. Em segundo lugar, esses serviços devem ser economicamente acessíveis, sem que seu consumo prejudique a realização de outros direitos garantidos no Pacto. Em terceiro lugar, essa acessibilidade deve se dar de forma não discriminatória. Por fim, deve haver acessibilidade em termos de informação, com participação social nas políticas públicas relativas à água.

\subsection{Deveres dos Estados perante seus cidadãos}

Aos direitos dos cidadãos correspondem deveres para os Estados. Aplicamse ao direito à água as cláusulas gerais do artigo 2 do Pidesc. Entre esses aspectos, deve-se destacar que, como direito humano de segunda geração, de caráter de prestação pelo Estado e dependente dos recursos disponíveis, o direito humano à água potável e saneamento está sujeito à progressiva realização pelos Estados, nos termos do artigo 2.1 do Pidesc. ${ }^{34}$

O Comentário 15 classifica em três tipos as obrigações para os Estados. Primeiramente, o Estado teria obrigação de respeitar esse direito no sentido negativo, ou seja, de não interferir com sua realização. Em segundo lugar, há a obrigação de proteger, o que significa impedir terceiros de intervir negativamente nessa realização, adotando a legislação necessária e, no caso de serviços privatizados, garantindo monitoramento independente, participação pública e penalidades por violações.

Há, por fim, um aspecto de prestação, traduzido pelo Comitê como obrigação de satisfazer ("fulfil"). Isso significa o dever do Estado de tomar medidas, dentro de suas possibilidades, para implementar esse direito. Para esses fins, o Estado deveria: a) facilitar o acesso a esse direito pelas diferentes comunidades; b) promover educação em higiene sanitária,

34 "Cada Estado membro no presente Pacto compromete-se a adotar medidas, tanto por esforço próprio como pela assistência e cooperação internacionais, principalmente nos planos econômico e técnico, até o máximo de seus recursos disponíveis, que visem a assegurar, progressivamente, por todos os meios apropriados, o pleno exercício dos direitos reconhecidos no presente Pacto, incluindo, em particular, a adoção de medidas legislativas". 
proteção das fontes de água e economia de água; e c) fornecer o direito, quando comunidades e indivíduos não puderem arcar com seus próprios meios. Este último aspecto poderia ser desenvolvido pelo Estado por diversos meios, como políticas de prestação de baixo custo ou gratuitas, ou políticas de complementação de renda.

Embora sujeito à realização progressiva, o Comitê identifica um núcleo duro de obrigações com efeitos imediatos e inderrogáveis. Essas obrigações consistiriam em: garantir quantidade mínima e segura para uso pessoal e doméstico para evitar doenças; não discriminação; assegurar o acesso físico à água; garantir distribuição igualitária de todas as fontes de água; adotar e implementar uma estratégia nacional sobre água; monitorar o grau de realização desse direito; adotar programas de baixo custo para grupos marginalizados; e prevenir, tratar e controlar doenças ligadas à água.

\subsection{Deveres dos Estados perante a sociedade internacional}

Por fim, o reconhecimento do direito humano à água potável e ao saneamento gera deveres limitados dos Estados perante a sociedade internacional.

A primeira questão diz respeito à inclusão da questão da água potável e saneamento nos relatórios internacionais dos órgãos de monitoramento de direitos humanos. A esse respeito, note-se que esse monitoramento já é feito não só no CDESC, mas também no Mecanismo de Revisão Periódica Universal do CDH, no Comitê sobre Direitos da Criança e no Comitê de Direitos Humanos. ${ }^{35}$

Além dessa obrigação, o Estado também deve respeitar a realização desse direito em outros países, o que significa não tomar medidas que possam prejudicar sua realização no exterior. O CDESC interpreta, a partir disso, uma proibição de utilização da água como instrumento de pressão política ou econômica. ${ }^{36}$ Todavia, não se pode esquecer do caráter limitado do direito à água como atualmente consagrado. Assim, deve-se ler esse dispositivo como uma proibição de utilizar a água como instrumento de pressão quando isso comprometer a utilização doméstica e pessoal garantida por esse direito. Em outros casos, parece prevalecer o direito soberano dos Estados sobre a utilização de seus recursos naturais.

\footnotetext{
35 Albuquerque, Catarina de \& Roaf, Virginia, On the Right Track: good practices in realising the rights to water and sanitation, 2012, pp. 199-200.

36 Comentário Geral No 15 , pp. 11-12.
} 
O direito à água também deve ser levado em conta ao elaborar instrumentos internacionais. O Comitê menciona especificamente a assinatura de tratados de liberalização comercial e a atuação de organismos financeiros em sua política de concessão de crédito e empréstimos. Esse último aspecto é relevante no caso de organismos internacionais, como o Banco Mundial, que, por vezes, condicionam o empréstimo de recursos financeiros à privatização dos serviços de água e saneamento, o que não necessariamente favorece o cumprimento do direito à água, que pode ser realizado por outras formas de prestação. ${ }^{37}$ Limitar políticas de cooperação à abordagem privatista, portanto, contribuiria de forma negativa à realização desse direito.

O Comitê propôs ainda que os Estados, em especial países desenvolvidos, tivessem o dever de auxiliar a realização desse direito em terceiros países: "Depending on the availability of resources, States should facilitate realization of the right to water in other countries, for example through provision of water resoures, financial and technical assistance, and provide the necessary aid when required".

Elaborada nesses termos, a proposta pode dar lugar a interpretações equivocadas. Melhor seria afirmar a necessidade de cooperação internacional para a realização desse direito, como é expresso no parágrafo $2 \mathrm{da}$ Resolução 64/292 da AGNU ou no parágrafo 10 da Resolução 15/9 do $\mathrm{CDH}$. Assim, garante-se não só uma concepção horizontal, mais condizente com a igualdade entre os Estados, mas coloca-se a questão em termos já estabelecidos no direito internacional dos direitos humanos, refletido no artigo 2.1 do Pidesc.

\section{Direito à água nos sistemas regionais de proteção aos direitos humanos}

Como bem analisou Jimena Murillo Chávarro, ${ }^{38}$ a questão do direito à água já começa a se fazer presente nos diferentes sistemas regionais de proteção aos direitos humanos, apesar de nenhum dos principais tratados garantir explicitamente esse direito.

No âmbito Interamericano, em 2007, a Assembleia Geral da Organização dos Estados Americanos (OEA) aprovou a Resolução 2349, que,

37 Bluemel, Erik, "The implications of formulating a human right to water", Ecology Law Quarterly, 2004, 31, p. 1003.

38 Murillo Chávarro, “The right to water...”, op. cit. 
embora não afirme explicitamente o direito humano à água, relaciona o acesso à água potável como essencial à dignidade, vida e saúde, ao "reconhecer e destacar que a água é essencial para a vida e a saúde de todos os seres humanos e que o acesso à água potável e à higiene básica é indispensável para viver com dignidade humana". 39

Já em 2012, por proposta boliviana, a Assembleia da OEA adota nova resolução, desta vez já intitulada "O Direito Humano à água potável e ao saneamento", formulação que só foi aprovada por consenso com a inclusão de notas de rodapé por Estados Unidos e Canadá expressando reservas a esse reconhecimento. ${ }^{40} \mathrm{O}$ preâmbulo dessa Resolução reafirma a "importância de que cada Estado continue se empenhando em assegurar aos indivíduos sujeitos à sua jurisdição, de acordo com sua legislação nacional, o acesso não discriminatório à água potável e ao saneamento como componentes integrais da realização de todos os direitos humanos". ${ }^{41}$

Do ponto de vista do sistema de proteção, a atuação da Corte e da Comissão Interamericanas em relação ao direito à água também tem avançado. Já começa a se formar um corpo jurisprudencial a respeito do direito à água no contexto de povos indígenas e de condições de encarceramento. Ademais, a Comissão tratou da questão em casos específicos, como a contaminação por petróleo na região de Oriente, no Equador, na década de $1990 .^{42}$

A Corte Interamericana tem lidado com casos de comunidades indígenas vivendo em terras não demarcadas e sob condições precárias, entre as quais a ausência de serviços de saneamento e a falta de fontes seguras de água potável. A Corte enquadrou a questão da falta de acesso à água de qualidade no contexto do direito à vida digna, um aspecto do direito à vida garantido pelo artigo $4^{\circ}$ do Pacto de San José. ${ }^{43}$

\footnotetext{
39 Organização dos Estados Americanos, Assembleia Geral, Resolução 2349, A água, a saúde e os direitos humanos, Doc. AG/REs. 2349 (XXXVII-O/07), Panamá, 5 jun. 2007.

40 Brzezinski, Maria Lúcia Navarro, "O direito à água no direito internacional e no direito brasileiro", Confluências, 2012, 14, (1), p. 71

41 Organização dos Estados Americanos, Assembleia Geral, Resolução 2760, O direito humano à água potável e ao saneamento, Doc. AG/RES. 2760 (XLII-O/12), Cochabamba, 5 jun. 2012.

42 Comissão Interamericana de Direitos Humanos, Informe sobre la situación de los derechos humanos en Ecuador, Doc. OEA/Ser.L/v/II.96, 24 abr. 1997.

43 Corte Interamericana de Direitos Humanos, Caso Comunidad Xákmok Kásek vs. Paraguay, sentença, 24 ago. 2010, pp. 194-196.
} 
Nos casos Comunidad Indígena Sawohayamaxa vs. Paraguai (2006) e Comunidad Xákmok Kásek vs. Paraguay (2010), a Corte considerou o Paraguai responsável por mortes de índios que viviam sob condições de risco, e condenou o Estado a administrar água potável suficiente para o consumo e higiene pessoal dos membros da comunidade e a criar serviços sanitários adequados nos assentamentos da comunidade. Também nos dois casos, a Corte determinou a criação de um fundo de desenvolvimento que teria, entre suas competências, projetos de abastecimento de água potável e construção de infraestrutura sanitária em benefício dos membros das comunidades. ${ }^{44}$

A Corte também já teve a oportunidade de analisar situações de prisões sem as adequadas condições de higiene e acesso seguro à água. Nos casos López. Álvarez vs. Honduras e Vélez Loorvs. Panamá considerou as situações degradantes como violações do direito ao tratamento humano e condenou os Estados a prover quantidade suficiente de água para consumo e higiene pessoais. ${ }^{45}$

A Corte Europeia de Direitos Humanos igualmente já analisou situação similar, e considerou que a privação de acesso à água constitui violação da proibição de tratamento desumano. ${ }^{46}$ Ainda no âmbito europeu, a questão também faz parte da agenda do Comitê Europeu dos Direitos Sociais, órgão de monitoramento da Carta Social Europeia. No caso European Roma Rights Centre v. Portugal (2011), o Comitê condenou Portugal em razão das precárias condições em que viviam comunidades ciganas nesse país. Em sua decisão, o Comitê reconheceu o direito à água potável e ao saneamento como consequência do direito à habitação, garantido no artigo 31 da Carta e determinou que os Estados devem garantir o acesso à água potável nos assentamentos dessas comunidades. ${ }^{47}$

No sistema africano, a questão da água tem assumido papel central, uma vez que diversos países garantem esse direito em suas legislações nacionais, em linha com a Declaração de Pretória sobre Direitos Socioeconômicos

44 Corte Interamericana de Direitos Humanos, Caso Comunidad Indígena Sawohayamaxa vs. Paraguay, sentença, 29 mar. 2006, \$224, 230. Corte Interamericana de Direitos Humanos, Caso Comunidad Xákmok Kásek vs. Paraguay, sentença, 24 ago. 2010, §301, 323.

45 Murillo Chávarro, “The right to water...”, op. cit., pp. 48-52.

46 Ibíd., p. 51.

47 Conselho da Europa, European Committee of Social Rights, European Roma Rights Centre v. Portugal, Complaint Nº 61/2010, Decision on the Merits, 30 jun. 2011, \$31-36. 
(2004), que prevê o acesso a saneamento básico e fornecimento adequado e seguro de água potável como consequência do direito à saúde. ${ }^{48} \mathrm{~A}$ Comissão Africana já teve diversas oportunidades de lidar com o assunto. Nos casos Free Legal Assistance Group and Other v. Zaire (2000), Social and Economic Rights Action Centre (Serac) \& Another v. Nigeria (2001) e Sudan Human Rights Organisation \& Another v. Sudan (2009), a Comissão tratou do acesso à água como consequência dos direitos à dignidade, à saúde e ao meio ambiente saudável, mas não o afirmou como direito autônomo, e aplicou consequências jurídicas limitadas. ${ }^{49}$ No caso Centre for Minority Rights Development (Kenya) and Minority Rights Group (on behalf of Endorois Welfare Council) vs. Kenya (2006), o acesso à água foi um dos fatores levados em conta no contexto da violação do direito ao desenvolvimento em razão da privação do acesso à terra da comunidade Endorois. ${ }^{50}$

\section{Perspectiva brasileira}

\subsection{Ordenamento jurídico}

O Brasil possui cerca de $12 \%$ das reservas de água doce do mundo, razão pela qual a análise da questão do direito humano à água sob a perspectiva brasileira assume grande relevância na discussão sobre as formas de distribuição desse recurso.

A Constituição Federal não prevê a proteção do direito à água entre o rol de direitos fundamentais. Wolkmer e Figueiró entendem que esse direito está implícito como "desdobramento do direito ao meio ambiente", 51 previsto no artigo 225. É certo que a água é um bem ambiental relevante e, nesse sentido, está presente no mandato constitucional de proteção ao meio ambiente. Não obstante, tutela constitucional da água e direito humano à água são conceitos distintos: o primeiro diz respeito ao dever do Estado de zelar pela sua preservação e utilização, ao passo que o segundo é mais

\footnotetext{
48 União Africana, Pretoria Declaration on Economic, Social and Cultural Rights in Africa, 2004, $\$ 7$.

49 Bulto, "The human right...", op. cit.

50 Murillo Chávarro, “The right to water...”, op. cit., pp. 62-63.

51 Figueiró, Fabiana \& Wolkmer, Maria de Fátima, "A interface da água enquanto recurso ambiental e econômico e sua interconexão com a tutela do meio ambiente", Revista Jurídica Cientifica do Centro de Ciências Jurídicas da Universidade Regional de Blumenau, 2013, 17, (34), p. 42.
} 
amplo e agregaria aos deveres do Estado uma série de direitos subjetivos, como tratado na seção 2. De uma certa forma, pode-se dizer que o aspecto ambiental é apenas uma das vertentes do direito à água.

Ainda assim, é relevante analisar como o acesso à agua e ao saneamento básico é tratado no ordenamento jurídico brasileiro e nas políticas públicas atualmente desenvolvidas, de forma a avaliar o reconhecimento ou promoção implícitos desse direito.

Os principais marcos legislativos da matéria são a Lei 9.433/97, que estabelece a Política Nacional de Recursos Hídricos, e a Lei 11.445/07, que estabelece a Política Federal de Saneamento Básico. A prestação dos serviços, no entanto, é de competência municipal, conforme o artigo 30, V, da Constituição Federal. ${ }^{52}$ Apesar disso, a maioria dos municípios ainda não tem legislação que regule água e saneamento. Para corrigir essa questão, a Lei 11.445/07 prevê a elaboração de políticas regionais com horizonte de vinte anos.

A gestão de serviços de água e esgoto é exclusivamente pública, com participação de atores privados no âmbito da prestação de serviços de distribuição e abastecimento e em parcerias público-privadas para a construção e operação de esgotos. O Ministério das Cidades é responsável pela questão do acesso à água potável e saneamento nas cidades com mais de 50 mil habitantes, ao passo que, nas cidades menores, essa competência cabe à Fundação Nacional de Saúde. Nos dois casos, há coordenação com a Agência Nacional de Águas (ANA).

Nesse conjunto legislativo, não há referência à garantia do acesso à água potável e ao saneamento como um direito humano, o que abre espaço para críticas legítimas sobre a negligência do legislador quanto a esse direito. ${ }^{53}$

Essa carência legislativa, no entanto, não tem impedido a promoção do acesso à água e saneamento na elaboração e execução de políticas públicas no Brasil, sob três vertentes: políticas sociais, planos de desenvolvimento e políticas de direitos humanos. Na primeira vertente, destaque-se o Plano Brasil Sem Miséria, com foco nas famílias com renda per capita inferior a $\mathrm{R} \$ 70,00$, e cujo eixo de acesso a serviços públicos inclui água e

52 "Art. 30. Compete aos Municípios: [...] V - organizar e prestar, diretamente ou sob regime de concessão ou permissão, os serviços públicos de interesse local, incluído o de transporte coletivo, que tem caráter essencial [...]”.

53 Brzezinski, “O direito à água...”, op. cit., pp. 60-82. 
esgoto. O plano almeja ampliar o acesso aos serviços de água e saneamento pela construção de moradias e cisternas. $\mathrm{Na}$ segunda vertente, cite-se a inclusão dos eixos Água e Luz para Todos e Cidade Melhor no II Plano de Aceleração do Crescimento. Por fim, o III Plano Nacional de Direitos Humanos trata da universalização dos serviços de abastecimento de água e esgoto na proposta sobre Garantia do Direito à Moradia.

Apesar disso, ainda há resistência em diversos âmbitos da administração pública e dos prestadores de serviços privados em relação a essa abordagem, o que ficará claro quando se tratar da jurisprudência relativa ao corte de água.

Segundo dados do Censo 2010, 61,8\% dos domić́lios no Brasil possuem saneamento adequado, entendidos como tais aqueles "com escoadouro ligado à rede geral ou à fossa séptica, servido de água proveniente de rede geral de abastecimento e com destino do lixo coletado diretamente ou indiretamente pelos serviços de limpeza". Embora ainda se esteja longe da universalização, sobretudo em regiões periféricas e cidades menores, verifica-se a progressiva realização do acesso ao saneamento, visto que em 1991 essa cobertura era de apenas 45,3\%. ${ }^{54}$

Levantamento da Secretaria Nacional de Saneamento Ambiental, no entanto, mostra um quadro menos favorável. Segundo o último Diagnóstico dos Serviços de Água e Esgotos, referente ao ano de 2013, o índice de atendimento alcança 82,5\% para rede de água, mas apenas 48,6\% para rede de coleta de esgoto. Ainda segundo o estudo, apenas 39\% dos esgotos gerados e $69,4 \%$ dos esgotos coletados no Brasil são tratados. ${ }^{55}$ Os índices tendem a ser piores nas áreas rurais. Há, portanto, um longo caminho a se trilhar para a promoção universal do acesso à água e ao saneamento no Brasil, sobretudo quanto à questão da coleta e tratamento de esgoto.

De toda forma, é digno de nota positiva a transparência e a participação na elaboração e execução das políticas públicas sobre a matéria, aspecto que é considerado referência positiva pela Relatora Especial da

\footnotetext{
54 Brasil, IBGE, "Indicadores sociais municipais: uma análise dos resultados do universo do Censo Demográfico 2010”, Estudos \& Pesquisas: informação Demográfica e Socioeconômica, 2011, (28).

55 Brasil, Ministério das Cidades, Secretaria Nacional de Saneamento Ambiental, Diagnóstico dos serviços de água e esgotos 2013, Brasília, dezembro 2014, em http://www. snis.gov.br/PaginaCarrega.php?EWRErterter'TERTer $=105$
} 
ONU, Catarina de Albuquerque. ${ }^{56} \mathrm{O}$ artigo $1^{\circ}$ da Lei $9.433 / 97$ garante a participação dos usuários e das comunidades na gestão dos recursos hídricos. A Lei 11.445/07, por sua vez, tem a transparência e o controle social como princípios fundamentais dos serviços públicos de saneamento básico (artigo $2^{\circ}$, IX e x).

Principal exemplo desse processo participativo foi a elaboração do Plano Nacional de Saneamento Básico (Plansab), sob responsabilidade do Conselho das Cidades (ConCidades), órgão formado por representantes do governo, setor produtivo, organizações sociais, ONGs, entidades profissionais, acadêmicas e de pesquisa, entidades sindicais. No contexto do ano internacional do saneamento, em 2008, o ConCidades adotou o "Pacto pelo Saneamento Básico: mais saúde, qualidade de vida e cidadania”, com diretrizes para a elaboração do Plansab. ${ }^{57} \mathrm{O}$ texto da proposta foi elaborado em 2011, e discutido em cinco seminários regionais e duas audiências públicas. O documento ainda passou por uma fase de consulta pública, pela internet, e foi submetido à análise dos Conselhos Nacionais de Saúde, de Meio Ambiente, de Recursos Hídricos e das Cidades. Somente após todas essas etapas, nas quais se buscou assegurar a mais ampla participação social, foi aprovado o Plano, em dezembro de 2013. ${ }^{58}$ Atualmente, o Plansab é o eixo central da política nacional para o saneamento básico, com o objetivo de universalizar o acesso aos serviços de saneamento básico como um direito social, com foco em grupos pobres e marginalizados.

\subsection{Estudo de caso: corte de água por inadimplemento}

Entre os diversos aspectos e formas de implementação do direito à água potável e ao saneamento, há uma questão bastante presente na jurisprudência brasileira. Trata-se da possibilidade de corte do fornecimento de água e esgoto para domicílios em caso de inadimplemento das faturas mensais.

A água é um recurso escasso e um bem econômico precioso. Sua elaboração como direito humano, entretanto, coloca limites a essa abordagem

\footnotetext{
56 Albuquerque \& Roaf, On the Right Track..., op. cit., pp. 54, 162.

57 Brasil, Ministério das Cidades, Pacto pelo Saneamento Básico: mais saúde, qualidade de vida e cidadania, Resolução Recomendada Nº 62, de 3 de Dezembro de 2008.

58 Brasil, Ministério das Cidades, Portaria Interministerial 571, de 6 de Dezembro de 2013, Aprova o Plano Nacional de Saneamento Básico (PNSB).
} 
puramente econômica. No Comentário 15, o CDESC afirma: "Water should be treated as a social and cultural good, and not primarily as an economic good". 59

Por outro lado, a prestação de serviço por delegação, modelo predominante no Brasil, implica a remuneração econômica pelos serviços prestados. A questão que se coloca é como lidar com casos em que há inadimplemento da contraprestação pecuniária por parte dos usuários. Dito de outra forma: como conciliar os dois aspectos da água: direito humano e bem econômico. A Lei 8.987/95, que regula a concessão de serviços públicos no Brasil, em seu artigo $6^{\circ}$, $\$ 3$, permite a interrupção da prestação do serviço "após aviso prévio por inadimplemento do usuário, considerado o interesse da coletividade". De forma semelhante, o artigo 40 da Lei 11.445/07 prevê a interrupção do serviço em caso de inadimplemento, desde que precedida de aviso prévio não inferior a 30 dias. O mesmo artigo estabelece restrições à interrupção de fornecimento a estabelecimentos de saúde, instituições educacionais e de internação coletiva e usuários de baixa renda beneficiários de tarifa social.

Diante do texto da lei, poder-se-ia pensar estarem estabelecidas todas as condições necessárias e suficientes para legitimar o corte do fornecimento de água em casos de não pagamento. A jurisprudência brasileira, no entanto, tem limitado essa possibilidade, em razão do caráter essencial do fornecimento de água. O Superior Tribunal de Justiça (STJ) tem firme jurisprudência no sentido da ilegalidade do corte no fornecimento de serviços públicos essenciais, como a água, quando a inadimplência do consumidor decorrer de débitos consolidados pelo tempo. ${ }^{60} \mathrm{Ou}$ seja, a suspensão só é possível no caso de inadimplemento contínuo e presente da contraprestação, e mediante aviso prévio. $^{61}$

Verifica-se, portanto, que a jurisprudência confere tratamento especial à proteção do acesso à água, estabelecendo condições (dívida presente) não previstas em lei. Tal interpretação, entretanto, não tem como fundamento o direito internacional dos direitos humanos, e sim o direito do consumidor, em especial o artigo 42 do Código de Defesa do Consumidor (Lei 8.078/1900), que impede o constrangimento como forma de

59 Comentário Geral No 15, p. 5.

60 Brasil, Superior Tribunal de Justiça, AgRg no Ag em REsp 247249-SP, Segunda Turma, Rel. Min. Mauro Campbell Marques, j. 21.02.2013.

${ }_{61}$ Ver, entre outros, Brasil, STJ, Rclm 5814-SE, Primeira Seção, Rel. Min. Humberto Martins, j. 14.09.2011. 
cobrança dívida. Evidência de que o foco dessa jurisprudência não é o direito humano à água é sua aplicação a empresas, apesar de seu uso não ser nem doméstico nem pessoal. ${ }^{62}$

Já há, todavia, julgados que vão além desse entendimento e proíbem o corte de água mesmo para dívidas presentes. Trata-se, sobretudo, de casos de órgãos públicos, como escolas ou hospitais, nos quais a interrupção do fornecimento prejudicaria não só o estabelecimento, mas a realização de direitos sociais como o direito à saúde e à educação. Assim, ainda que não se trate de uso doméstico ou pessoal, esses julgados buscam concretizar o direito à água em sua relação com outros direitos reconhecidos e tutelados de forma mais ampla no direito internacional dos direitos humanos:

[...] A água é, na atualidade, um bem essencial à população, constituindo-se serviço público indispensável, subordinado ao princípio da continuidade de sua prestação, pelo que se torna impossível a sua interrupção. [...].

a jurisprudência predominante vem decidindo que: [...] "no caso dos autos, pretende a recorrente o corte no fornecimento de energia elétrica do único hospital público da região, o que se mostra inadmissível em face da essencialidade do serviço prestado pela ora recorrida. Nesse caso, o corte da energia elétrica não traria apenas desconforto ao usuário inadimplente, mas verdadeiro risco à vida de dependentes dos serviços médicos e hospitalares daquele hospital público. $\mathrm{O}$ art. $6^{\circ}$, $\rrbracket 3^{\circ}$, inciso II, da Lei n. 8.987/95 estabelece que é possível o corte do fornecimento de energia desde que considerado o interesse da coletividade. Logo, não há que se proceder ao corte de utilidades básicas de um hospital, como requer o recorrente, quando existem outros meios jurídicos legais para buscar a tutela jurisdicional (Resp. No 876723/ PR, $2^{\mathrm{a}}$ Turma, Rel. Min. Humberto Martins, DJ de 05.02.2007); [...]. ${ }^{63}$

Não obstante esses desenvolvimentos positivos, ainda há muito espaço para o tratamento da questão da água e saneamento no Brasil sob a perspectiva dos direitos humanos. É necessário que planejadores e

62 Brasil, Superior Tribunal de Justiça, AgRg no AI 307905-PB, Primeira Turma, Rel. Min. José Delgado, j. 10.10.2000.

63 Brasil, Superior Tribunal de Justiça, Resp. 943.850-SP, Primeira Turma, Rel. Min. José Delgado, j. 28.08.2007. 
gestores de políticas públicas, empresas prestadoras de serviços e o Poder Judiciário estejam conscientes de que água potável segura e o saneamento para uso doméstico e pessoal são direitos humanos que merecem proteção.

Os casos de inadimplemento e corte de água revelam a centralidade da questão da acessibilidade econômica para o objetivo da universalização do acesso à água. A acessibilidade econômica é um dos elementos constitutivos do direito à água, que pode ser realizado por três tipos de medidas. Uma dessas formas é a adoção de programas de complementação de renda ou renda mínima, sendo o exemplo mais conhecido o Programa Bolsa Família, que aumentam o orçamento familiar de forma geral, possibilitando o pagamento dos custos básicos de vida. Outra maneira é o fornecimento gratuito de água pelo Estado, a exemplo da construção de cisternas no contexto do Plano Brasil Sem Miséria, cujo foco são as famílias com renda per capita inferior a $\mathrm{R} \$ 70,00$. Por fim, outra forma de compatibilizar esses dois aspectos é o fornecimento de água a baixo custo, por meio de programas de tarifa social, adotados pelas prestadores de serviços.

As duas primeiras estratégias mencionadas podem ser realizadas por políticas sociais de diversos níveis de governo. A hipótese de fornecimento a baixo custo, por outro lado, dado o caráter descentralizado dos serviços de água e esgoto, depende de iniciativas locais dos Municípios ou das empresas distribuidoras. A ampliação dessas políticas é essencial para a compatibilização de um modelo de remuneração e recuperação de custos pelas empresas com uma abordagem da água e saneamento sob a perspectiva dos direitos humanos, mostrando a compatibilidade entre a privatização de serviços e a abordagem econômica com a realização do direito à água e saneamento. ${ }^{64}$

\section{Conclusão}

A análise realizada mostra que, com base no direito costumeiro e na interpretação dos tratados que formam o direito internacional dos direitos humanos, pode-se afirmar que existe um direito humano à água, ainda que limitado ao direito à água potável e ao saneamento para uso pessoal e doméstico. Trata-se de um direito autônomo, mas que deve ser lido em conjunto com outros direitos, em especial os direitos à vida digna, à saúde, à moradia e à alimentação.

64 Compatibilização também demonstra por Murthy, "The human right(s)...”, op. cit. 
As obrigações específicas que derivam do direito à água ainda não são claras e estão sendo delimitadas com o envolvimento dos tribunais nacionais e dos órgãos do sistema internacional de proteção aos direitos humanos. Esse desenvolvimento percorre caminho tortuoso em razão de diferentes concepções sobre o acesso à água, o que se buscou ressaltar por meio do contraste entre propostas privatistas e desenvolvimentistas, evidenciado pela oposição simbólica entre Genebra e Nova Iorque.

O Brasil ocupa posição privilegiada no debate sobre o direito à água. Os programas sociais e de desenvolvimento interno projetam o país a lugar de destaque no plano internacional na questão do acesso à água. Ainda assim, há resistências da burocracia estatal e das empresas prestadoras de serviço, razão pela qual se deve continuar a promover a conscientização sobre a perspectiva da água como direito humano. A melhor delimitação dos deveres dele advindos também facilitaria sua implementação.

Tendo em vista a prioridade da universalização dos serviços de água e saneamento, a questão mais atual desse debate é o aspecto de acessibilidade da água. No Brasil, existem políticas públicas voltadas à promoção do acesso universal à água e saneamento. Não obstante, a compatibilização desse direito com a prestação de serviços por regime de delegação requer a adoção de regulação e fiscalização por parte do Estado, incentivando políticas que garantam não só o acesso físico, mas também o acesso econômico de todas as pessoas aos serviços de água potável e saneamento.

\section{Referências bibliográficas}

\section{Artigos e livros}

Albuquerque, Catarina de \& Roaf, Virginia, On the Right Track: goodpractices in realising the rights to water and sanitation, 2012, em http://www.ohchr.org/Documents/Issues/Water/BookonGoodPractices_en.pdf, acesso em 12 fev. 2015.

Bluemel, Erik, "The implications of formulating a human right to water", Ecology Law Quarterly, 2004, 31, pp. 957-1006.

Brzezinski, Maria Lúcia Navarro, "O Direito à água no direito internacional e no direito brasileiro", Confluências, 2012, 14, (1), pp. 60-82.

Bulto, Takele Soboka, "The human right to water in the corpus and jurisprudence of the African human rights system", African Human Rights Law Journal, 2011, 11, (2), pp. 341-367. 
Cahill, Amanda, "The human right to water - a right of unique status': the legal status and normative content of the right to water", The International Journal of Human Rights, 2005, 9, (3), pp. 389-410.

Figueiró, Fabiana \& Wolkmer, Maria de Fátima, "A interface da água enquanto recurso ambiental e econômico e sua interconexão com a tutela do meio ambiente", Revista Jurídica Científica do Centro de Ciências Jurídicas da Universidade Regional de Blumenau, 2013, 17, (34), pp. 37-56.

Finnemore, Martha \& Sikkink, Kathryn, "International norm dynamics and political change", International Organization, 1998, 52, (4), pp. 887-917.

Galindo, George Rodrigo Bandeira, "A volta do terceiro mundo ao direito internacional", Boletim da Sociedade Brasileira de Direito Internacional, 2013, 119-124, pp. 46-68.

Gleick, Peter H., “'The human right to water”, Water Policy, 1998, 1, (5), pp. 487-503.

Hiskes, Richard P., "Missing the green: golf course ecology, environmental justice, and local 'fulfillment' of the human right to water", Human Rights Quarterly, 2010, 32, (2), pp. 326-341.

Jochnik, Chris Af \& Normand, Roger, "The legitimation of violence: a critical history of the laws of war", Harvard Journal of International Law, 1994, 35, (1), pp. 49-95.

Koller, David, “... and New York and The Hague and Tokyo and Geneva and Nuremberg and...: the geographies of international law", The European Journal of International Law, 2012, 23, (1), pp. 97-119.

Langford, Malcolm, "Ambition that overleaps itself? A response to Stephen Tully's critique of the General Comment on the right to water", Netherlands Quarterly of Human Rights, 2006, 24, (3), pp. 433-459.

McGraw, George S., "Defining and defending the right to water and its minimum core: legal construction and the role of national jurisprudence", Loyola University Chicago International Law Review, 2011, 8, (2), pp. 101-185.

Murillo Chávarro, Jimena, "The right to water in the case-law of the InterAmerican Court of Human Rights", Anuario Colombiano de Derecho Internacional, 2014, 7, pp. 39-68.

Murthy, Sharmila L., "The human right(s) to water and sanitation: history, meaning and the controversy over privatization", Berkeley Journal of International Law, 2013, 31, (1), pp. 89-147.

Tully, Stephen, "A human right to access water? A critique of General Comment No 15", Netherlands Quarterly of Human Rights, 2005, 23, (1), pp. 35-63. 
Wolkmer, Antonio Carlos; Augustin, Sergio; Wolkmer, Maria de Fátima S., "O 'novo' direito à água no constitucionalismo da América Latina", in Wolkmer, Maria de Fátima S. \& Melo, Milena Petters (Orgs.), Crise ambiental, direitos à água e sustentabilidade: visões multidisciplinares, Educs, Caxias do Sul, 2012, pp. 47-65.

\section{Documentos}

Brasil, IBGE, "Indicadores sociais municipais: uma análise dos resultados do universo do Censo Demográfico 2010”, Estudos \& Pesquisas: informação Demográfica e Socioeconômica, 2011, (28).

Brasil, Ministério das Cidades, Pacto pelo Saneamento Básico: mais saúde, qualidade de vida e cidadania, Resolução Recomendada No 62 , de 3 de Dezembro de 2008.

Brasil, Ministério das Cidades, Portaria Interministerial 571, de 6 de Dezembro de 2013, Aprova o Plano Nacional de Saneamento Básico (PNSB).

Brasil, Ministério das Cidades, Secretaria Nacional de Saneamento Ambiental, Diagnóstico dos serviços de água e esgotos 2013, Brasília, dezembro 2014, em http://www.snis.gov.br/PaginaCarrega. php?EWRErterterTERTer $=105$

Comissão Interamericana de Direitos Humanos, Informe sobre la situación de los derechos bumanos en Ecuador, Doc. OEA/Ser.L/v/II.96, 24 abr. 1997.

Conselho da Europa, European Committee of Social Rights, European Roma Rights Centre v. Portugal, Complaint No 61/2010, Decision on the Merits, 30 jun. 2011.

International Law Association, Berlin Conference (2004), Water Resources Law, 2004.

Organização das Nações Unidas, Assembleia Geral, Resolução 54/175, The right to development, UN Doc. A/RES/54/175, Nova Iorque, 17 dez. 1999.

Organização das Nações Unidas, Assembleia Geral, Resolução 64/292, The human right to water and sanitation, UN Doc. A/RES/64/292, Nova Iorque, 28 jul. 2010.

Organização das Nações Unidas, Assembleia Geral, un Doc. A/64/PV.108, Nova Iorque, 28 jul. 2010.

Organização das Nações Unidas, Conselho de Direitos Humanos, Decisão 2/104, Human rights and access to water, Genebra, 27 nov. 2006.

Organização das Nações Unidas, Conselho de Direitos Humanos, Reso- 
lução $7 / 22$, Human rights and access to safe drinking water and sanitation, UN Doc. A/HRC/RES/7/22, Genebra, 28 mar. 2008.

Organização das Nações Unidas, Conselho de Direitos Humanos, Resolução 15/9, Human rights and access to safe drinking water and sanitation, UN Doc. A/HRC/RES/15/9, Genebra, 30 set. 2010.

Organização das Nações Unidas, Conselho de Direitos Humanos, Resolução 16/2, The human right to safe drinking water and sanitation, UN Doc. A/HRC/RES/16/2, Genebra, 24 mar. 2011.

Organização das Nações Unidas, Conselho Econômico e Social, Comitê sobre Direitos Econômicos, Sociais e Culturais, General Comment No 15 (2002), uN Doc. E/C.12/2002/11, Genebra, 29 nov. 2002.

Organização das Nações Unidas, Report of the United Nations Water Conference, Mar del Plata, 14-25 March 1977, un Doc.E/conf.70/29, Nova Iorque, 1977.

Organização das Nações Unidas para Alimentação e Agricultura, Water Reports, No 23: Review of world water resources by country, 2003. Organização dos Estados Americanos, Assembleia Geral, Resolução 2349, A água, a saúde e os direitos humanos, Doc. AG/RES. 2349 (xxXVII-O/07), Panamá, 5 jun. 2007.

Organização dos Estados Americanos, Assembleia Geral, Resolução 2760, $\mathrm{O}$ direito humano à água potável e ao saneamento, Doc. AG/RES. 2760 (XLII-O/12), Cochabamba, 5 jun. 2012.

União Africana, Pretoria Declaration on Economic, Social and Cultural Rights in Africa, 2004.

\section{Decisões judiciais}

Corte Interamericana de Direitos Humanos, Caso Comunidad Indígena Sawohayamaxa vs. Paraguay, sentença, 29 mar. 2006.

Corte Interamericana de Direitos Humanos, Caso Comunidad Xákmok Kásek vs. Paraguay, sentença, 24 ago. 2010.

Brasil, Superior Tribunal de Justiça, AgRg no Ag em Resp. 247249-SP, Segunda Turma, Rel. Min. Mauro Campbell Marques, j. 21.02.2013. Brasil, Superior Tribunal de Justiça, AgRg no AI 307905-PB, Primeira Turma, Rel. Min. José Delgado, j. 10.10.2000.

Brasil, Superior Tribunal de Justiça, Rclm 5814-SE, Primeira Seção, Rel. Min. Humberto Martins, j. 14.09.2011.

Brasil, Superior Tribunal de Justiça, Resp. 943.850-SP, Primeira Turma, Rel. Min. José Delgado, j. 28.08.2007. 
